\title{
Mandatory continuing education for psychologists: Practitioners' views
}

\author{
A L Pillay, PhD; A Zank, MA \\ Department of Behavioural Medicine, College of Health Sciences, University of KwaZulu-Natal, Durban, South Africa
}

Corresponding author: A L Pillay (anthony.pillay@kznhealth.gov.za)

Background. With the system of mandatory continuing professional development (CPD) for psychologists in its second decade in South Africa (SA), research into practitioners' views of and experiences with the system is almost non-existent. The current research is necessary to help to inform future developments in this subject area.

Objectives. To understand psychologists' experiences with the mandatory continuing education system, including their attitudes, means of accessing $\mathrm{CPD}$, barriers and perceived improvements in knowledge and skills.

Methods. A survey approach was used to ascertain feedback from clinical, counselling and educational psychologists in KwaZulu-Natal Province, SA. Questions addressed means of accessing CPD activities, relevance to practitioners, whether continuing education needs were being met, topics that should be covered, perceived impact of CPD on practice, cost implications and experiences of being audited by the Health Professions Council of SA (HPCSA). Descriptive statistics were computed to analyse emerging trends.

Results. A total of 204 completed practitioner responses (response rate $28.2 \%$ ) were received, of whom 55.4\% agreed with the mandatory CPD policy, $91.7 \%$ noted that they would pursue continuing education even if not compulsory, and $84.3 \%$ stated that their continuing education needs were being met. About three-quarters of the participants felt that CPD costs were excessive, $70.1 \%$ self-funded their $\mathrm{CPD}$, and $46.8 \%$ reported being audited by the HPCSA, of whom $49 \%$ had not met the requirements.

Conclusion. Despite the finding that close to half of the sample opposed the idea of mandatory CPD, the expressed willingness to engage in continuing education is a positive sign. Cost as the major barrier will need to be examined as one of the factors that could enhance CPD compliance.

Afr J Health Professions Educ 2018;10(4):215-219. DOI:10.7196/AJHPE.2018.v1014.1049

Continuing education has long been recognised as a critical feature of upskilling and keeping health practitioners abreast of the latest developments in their field. The value of such post-qualification education for improved patient care forms the main thrust that drives continuing education initiatives. Historically, however, this was regarded as a voluntary form of self-development.

While compulsory continuing education regulations for health professionals, including psychologists, have been in place in some countries for many years, regulatory developments in the South African (SA) context have occurred mainly in the past two decades, with some professions, e.g. nursing, yet to implement such regulations. A study of nurses showed that $39.4 \%$ were against such regulation. ${ }^{[1]}$ The term continuing professional development (CPD) has been coined to refer to the regulated continuing education system in the country, and the current article uses the terms CPD and continuing education interchangeably.

For psychologists to maintain their licence and registration with the Health Professions Council of South Africa (HPCSA), they need to accumulate $30 \mathrm{CPD}$ points each year, with at least 5 points in the area of ethics, human rights or medical law. ${ }^{[2]}$ One CPD point is earned for each hour of an accredited learning activity, and CPD activities can include workshops, conferences, symposia, journal clubs and other similar professional activities. The rationale for mandatory continuing education lies in the necessity for healthcare practitioners to keep abreast of developments in their field to provide optimal, evidence-informed, patient care. ${ }^{[3]}$ In addition to traditional formats of continuing education, online learning systems provide a further option for practitioners. While most young people are adept at (and even prefer) digital technology, this does not translate straightforwardly to online learning. A recent Irish study of diagnostic radiographers revealed that about half of their participants were not very confident using online learning systems. ${ }^{[4]}$

Mulvey ${ }^{[5]}$ identified three key role-players in the CPD system, i.e. the individual practitioner, the employer and the professional body. Such a conceptualisation is useful because it acknowledges the critical role of each in ensuring the ultimate goal of best practice and optimal patient care. The practitioner and the employer have direct responsibility towards patient care, while the professional body has the task of safeguarding the public by regulating health professionals' behaviour, ethical practice and adherence to appropriate standards of healthcare. However, CPD compliance can be costly in terms of time and money, with implications for the practitioner and in some cases for the employer. Grehan et al. ${ }^{[4]}$ found that funding, time and location were significant barriers to CPD compliance. Notwithstanding the cost-bearers of continuing education, there has been concern about costeffectiveness issues relating to $\mathrm{CPD}$ activities. ${ }^{[6]}$

While there has been concern about the extent to which collecting CPD points results in improved practitioner skills or improved service, ${ }^{[5]}$ the findings have been varied. Although it is difficult to directly attribute patient outcomes to continuing education initiatives, there is evidence that professional education influences changes in practice and enhances 
practitioner competencies and confidence. ${ }^{[7]}$ Such growth and development are essential, and Balmer ${ }^{[8]}$ describes how the level of competence for each professional changes over time from the completion of the initial academic degree as a novice and to the level of an expert later in their career when intuitive implementation of skills is evident?'

It is also noted that continuing education formats and outcome measurements may need scrutiny, with attendance and time-based measures not being regarded as sole requirements. A focus on the competencies achieved could be a more meaningful approach. ${ }^{[8]}$ Similarly, Boud and Hager ${ }^{[9]}$ suggested that CPD may be better served if it is located within practice theory. They argued against the current trends of having professionals participate in training programmes that are independent of their practice contexts. Situation-specific and relevant training makes sense, especially for middle- and lower-income countries, where practice contexts can be vastly different to CPD classrooms. Similarly, a study of Malaysian general medical practitioners (GPs) noted favourable self-reports of CPD, even considering it an investment with potential for good return, but also felt that locally initiated programmes would be more relevant to their practices ${ }^{[10]} \mathrm{A}$ recent African study of $\mathrm{CPD}$ for medical and nursing professionals in Tanzania, Malawi and SA also recommended that programmes should reflect the disease contexts of the communities served and that workplace mentorship was preferable to classroom-based teaching. ${ }^{[1]}$

Against this background, the authors, who are CPD providers, deemed it necessary to engage practitioners in exploratory research to gauge their views on various CPD matters. The objectives of this study were to understand practising psychologists' experiences of complying with CPD requirements, their views on its professional relevance, the means by which they access continuing education, accessibility of programmes, issues relating to cost, their views on who the providers should be, as well as participants' experiences of the auditing system. To the authors' knowledge, these issues have not been evaluated to any significant degree among psychologists in SA. A previous SA study looked at CPD among mental health practitioners as a group, with only partial focus on psychologists. ${ }^{[12]}$

\section{Methods Participants}

Clinical, counselling and educational psychologists in KwaZulu-Natal (KZN) Province, who were registered as such with the HPCSA, were approached regarding participation. These three categories of psychologists were identified for the study, as they are psychology professionals who are in practice in healthcare and educational settings - unlike the other two categories in the country (industrial/organisational and research). While an ideal approach would have included all of the psychologists registered in these categories throughout SA, the complexity of such a task, including lack of electronic access to all (as the HPCSA does not store email addresses of all practitioners), made such an endeavour beyond the scope of this work, and not necessarily as meaningful and productive. Moreover, given that KZN is one of the two largest provinces in the country, comprising almost one-fifth of the national population, ${ }^{[13]}$ there is reason to believe that findings from a study in this province will be reasonably representative of the national situation. Furthermore, as the authors provide regular CPD programmes in KZN, they have relatively good access to email databases for psychologists in the three registration categories in the province, thus improving the likelihood of a desirable response rate. At the time of the investigation there were 722 licensed practitioners in the three categories in KZN (clinical: $n=326$, counselling: $n=232$, educational: $n=164$ ) (HPCSA personal communication, 14 July 2016).

\section{Instrument}

The authors developed a questionnaire, as there were no established instruments. The questions were devised to address the issues they were interested in, and were based on their experiences with the provision of CPD programmes provincially and nationally, as well as collegial feedback regarding CPD involvement and compliance. Apart from basic demographics, the instrument tapped participant views, attitudes and experiences of the CPD system in the following areas: work and practice context; means of accessing CPD activities; relevance of the CPD system to practitioners; whether continuing education needs were being met; topics that should be covered; perceived impact of CPD on practice; cost implications of CPD; and experiences of being audited by the HPCSA.

\section{Procedure}

An online survey approach was used. The population of clinical, counselling and educational psychologists in KZN was accessed through the use of multiple data sources that included the various professional association databases, as well as the authors' own databases of CPD-registered participants throughout the province. An invitation to participate was emailed to psychologists registered on the databases, providing the URL link to access the study, should they choose to do so. The link opened to the introductory page, which described the study, its purpose, estimated completion time, as well as voluntary participation details. The sample comprised all those who agreed to participate in the survey and provided complete responses. Anonymity was ensured with the online programme used.

\section{Ethical approval}

The study received ethical approval from the University of KZN Humanities and Social Sciences Research Ethics Committee (ref. no. HSS/1757/015). The introductory information on the online administration system made it clear that participation was voluntary and that the participants could withdraw at any stage.

\section{Data analysis}

Data were analysed using SPSS 25 (IBM Corp., USA) to examine emerging trends. Descriptive statistics were computed to identify variables of significance.

\section{Results}

A total of 204 completed responses were received; all were included in the study. This constituted a response rate of $28.2 \%$, which may be somewhat lower than desired, but is understandable given the tendency among practitioners to ignore research participation requests either through electronic or postal mail. Women comprised the majority ( $n=176 ; 86.3 \%)$ of the participants, while the age range was 29 - 72 (mean 40.44, standard deviation (SD) 7.09) years. Duration of practice ranged from 1 to 41 (mean 11, SD 6.3) years. Although the professional registration categories of the participants appeared relatively evenly distributed, with 71 (34.8\%) counselling psychologists, 65 (31.9\%) clinical psychologists and 64 (31.4\%) educational psychologists, the proportional representation was skewed. The 
category response rates were as follows: $39.0 \%$ educational psychologists, $30.6 \%$ counselling psychologists and $19.9 \%$ clinical psychologists. Although the overall response rate was lower than ideal, earlier professional psychology research has documented similar rates of survey response. ${ }^{[14,15]}$

Table 1 shows the participants' primary place of employment. Of those working in government departments, health (51.0\%) and education (41.2\%) were the predominant contexts.

Table 2 reflects the means used by participants in accessing CPD activities. More than half of the participants $(n=115 ; 56.4 \%$ ) reported having problems accessing CPD activities. The types (areas) of problems experienced are reflected in Table 3 .

While $113(55.4 \%)$ of the sample agreed with the policy of mandatory CPD, 89 (43.6\%) believed that CPD should not be mandatory. However, the overwhelming majority of participants $(n=187 ; 91.7 \%)$ stated that they would undertake professional development activities even if CPD was not compulsory. In a similar vein, $172(84.3 \%)$ of the sample noted that their continuing education needs were currently being met.

Table 4 shows the areas where participants reported that their knowledge and skills have improved. Participants' responses regarding who they believed should provide CPD activities are listed in Table 5.

Participants' views on the extent to which current CPD activities address specific aspects are reflected in Table 6. Regarding the funding of CPD

\begin{tabular}{ll} 
Table 1. Primary place of employment & \\
\hline Employment & $\boldsymbol{n}(\%)$ \\
\hline Private practice & $75(36.8)$ \\
University and private practice & $50(24.5)$ \\
Government department & $30(14.7)$ \\
Government and private practice & $19(9.3)$ \\
Private practice and other & $15(7.4)$ \\
University & $7(3.4)$ \\
Other & $6(6.0)$ \\
Missing & $2(1.0)$ \\
Total & $204(100)$
\end{tabular}

\section{Table 2. Means of accessing CPD activities}

\begin{tabular}{ll}
\hline Access to CPD & $\boldsymbol{n}(\%)$ \\
\hline Workshops & $184(90.6)$ \\
Symposia or conferences & $155(77.3)$ \\
Journal clubs/professional groups & $142(70.0)$ \\
Online activities & $45(22.2)$ \\
Other & $5(2.5)$ \\
CPD $=$ continuing professional development. &
\end{tabular}

\section{Table 3. Problems experienced in accessing CPD activities}

\begin{tabular}{ll}
\hline Problems & $\boldsymbol{n}(\%)$ \\
\hline Physical accessibility & $45(22.2)$ \\
Time to attend & $105(51.7)$ \\
Availability/awareness & $2(1.0)$ \\
Cost & $115(56.7)$ \\
Topics covered not of interest & $40(19.7)$ \\
Other & $0(0.0)$ \\
CPD = continuing professional development. &
\end{tabular}

activities, 143 (70.1\%) of participants reported self-funding their continuing education, while about one-quarter $(n=53 ; 26.0 \%)$ indicated joint funding by themselves and their employers. Most participants ( $n=156 ; 76.5 \%)$ felt that the cost of CPD was excessive, while 40 (19.6\%) considered the activities reasonably priced. Close to half of the participants $(n=95 ; 46.8 \%)$ reported that they had been audited by the HPCSA regarding their CPD compliance, and $49 \%$ of those had not met the requirements immediately.

Responding to the question of providing CPD activities, 164 (80.4\%) stated that they do not provide or initiate such activities, with 28 (13.7\%) stating that they do. Of the latter, most $(n=17 ; 63.0 \%)$ found the application process for CPD accreditation easy to follow and 20 (83.3\%) noted that their applications were processed in a timely manner. Nearly all of the CPD providers in the sample $(n=21 ; 91.3 \%)$ had not had their events audited.

Table 7 reflects the broad areas of psychology that participants requested as CPD programmes of choice for future programmes.

Table 8 presents the gender effects on selected variables. Significantly more men than women reported being audited and agreed with mandatory $\mathrm{CPD}$, but considering sample gender distribution these interaction effects should not be over-stated.

Being in full-time private practice had no influence on participants experiencing problems in accessing CPD $\left(\chi^{2} 0.152 ; p=0.697\right)$, agreement with mandatory CPD policy ( $\left.\chi^{2} 0.005 ; p=0.945\right)$, willingness to undertake CPD regardless of legislation $\left(\chi^{2} 0.786 ; p=0.375\right)$ or whether they were audited ( $\chi^{2}$ 0.082; $p=0.775$ ). However, significantly more participants in

\begin{tabular}{lll}
\multicolumn{3}{l}{ Table 4. Knowledge and skills improvement because of CPD } \\
\hline Areas of improvement & Improved, $\boldsymbol{n}$ (\%) & Not improved, $\boldsymbol{n}$ (\%) \\
\hline Practical skills & $158(77.5)$ & $45(22.1)$ \\
Theoretical knowledge & $152(74.5)$ & $51(25.0)$ \\
Ethics, legal or human rights & $180(88.2)$ & $23(11.3)$ \\
knowledge & & \\
CPD = continuing professional development. &
\end{tabular}

\begin{tabular}{ll} 
Table 5. Preferred CPD providers & \\
\hline Preferred provider & $\boldsymbol{n}(\%)$ \\
\hline University & $198(97.5)$ \\
Professional association & $144(70.9)$ \\
Interest group & $57(28.1)$ \\
Employing organisation & $43(21.2)$ \\
Other & $8(3.9)$ \\
$\mathrm{CPD}=$ continuing professional development. &
\end{tabular}

Table 6. Adequacy of CPD activities in addressing specific areas

\begin{tabular}{lll}
\hline Activity & $\begin{array}{l}\text { Adequately } \\
\text { addressed, } \boldsymbol{n}(\%)\end{array}$ & $\begin{array}{l}\text { Not adequately } \\
\text { addressed, } \boldsymbol{n}(\%)\end{array}$ \\
\hline Basic knowledge & $154(75.5)$ & $48(23.5)$ \\
$\begin{array}{l}\text { Updating latest } \\
\text { professional developments }\end{array}$ & $168(82.4)$ & $33(16.2)$ \\
$\begin{array}{l}\text { Refresher courses } \\
\text { Specialised techniques }\end{array}$ & $169(82.8)$ & $31(15.2)$ \\
CPD = continuing professional development. & $73(35.8)$
\end{tabular}


full-time private practice viewed CPD costs as excessive than those who were not in full-time private practice $\left(\chi^{2} 5.853 ; p=0.016\right.$, Cramer's V 0.173$)$. More participants who reported that their continuing education needs were currently met were not in full-time private practice, although this finding fell slightly short of significance $\left(\chi^{2} 3.500 ; p=0.061\right)$.

\section{Discussion}

The substantially higher proportion of responses from educational and counselling psychologists than clinical psychologists is interesting. Among the reasons might be the heightened concern among educational and counselling psychologists in recent years regarding professional training and scope of practice issues. These matters have dominated the discipline of psychology and led to court action and pressure on the HPCSA to address the scope of practice legislation. The preponderance of women in the sample is in keeping with the gender distribution trends in psychology locally and internationally, with some referring to this development as the 'feminisation of psychology'.16]

The means of accessing continuing education reveals interesting trends. Clearly, the majority of participants preferred group-based learning contexts with peers, and $>90 \%$ favoured workshops, suggesting the need for skills acquisition that workshops generally deliver. This is similar to the transnational African study findings that show a preference for workplacebased mentoring, which also emphasised practical skills development as opposed to theory uptake. ${ }^{[1]}$ It is encouraging to note that $70 \%$ of participants were involved in journal clubs or professional groups, which are generally self-selected peer-groupings for practitioners who desire

\begin{tabular}{ll}
\multicolumn{2}{l}{ Table 7. Desired CPD topics for future programmes } \\
\hline Topics & $\boldsymbol{n}(\%)$ \\
\hline Therapy & $84(41.4)$ \\
Ethics & $29(14.3)$ \\
Forensics & $29(14.3)$ \\
Specific disorders & $26(12.8)$ \\
Assessment & $24(11.8)$ \\
Neuropsychology & $16(7.9)$ \\
Corporate-related work & $10(4.9)$ \\
Theories & $9(4.4)$ \\
Career/vocational counselling & $8(3.9)$ \\
Pharmacotherapy & $6(3.0)$ \\
Research & $5(2.5)$ \\
Culture & $2(1.0)$ \\
Other & $11(5.4)$ \\
CPD $=$ continuing professional development. &
\end{tabular}

collegial interaction and support, as opposed to insular ways of working and learning. The finding that less than one-quarter of participants used online offerings is slightly unexpected, considering the relatively young sample and the plethora of marketing of online CPD programmes. However, the finding seems to align with that of Grehan et al. ${ }^{[4]}$ who noted that about half of their sample was not sufficiently confident with online learning systems.

The finding that over half of participants experienced problems accessing CPD activities, with cost and time being the major barriers, is of concern. While similar to the finding of Grehan et al. ${ }^{[4]}$ in Ireland, the related matter of cost-effectiveness ${ }^{[6]}$ is one that needs ongoing monitoring and evaluation, especially considering the prolific marketing of CPD activities nationally. Close to half the sample believed that CPD should not be mandatory, which is a slightly higher proportion than that found in an earlier SA study of nurses. ${ }^{[1]}$ This very possibly reflects the preference for autonomous decision-making in continuing education, because $>90 \%$ of the current sample conceded that they would undertake continuing education even if it was not mandatory. The positive reports by about three-quarters of the participants regarding perceived improvement in their knowledge, should be viewed against the very prominent view (close to half the sample) that CPD should not be compulsory, suggesting that perhaps mandatory CPD has been fruitful. This is consistent with the finding of Abdul Samad et al. ${ }^{[10]}$ regarding general practitioner reports on the positive benefits of mandatory $\mathrm{CPD}$. The more substantive improvement reported in knowledge of ethics, law and human rights must be viewed in a positive light, given SA's not-sodistant history of serious human rights abuses, as well as the relatively recent uncovering of US psychologists' complicity in torture and human rights violations at Guantanamo Bay. ${ }^{[17,18]}$

Participants' preference for universities and professional associations as the main providers of CPD programmes is not surprising, considering that the former are the purveyors of academic and scientific knowledge and the primary source of participants' basic professional education, while the latter are charged with professional growth and development of the discipline. Participants were generally satisfied with the adequacy of CPD activities addressing most areas, but were relatively less impressed with the extent to which specialised techniques were covered. The greater quest for knowledge in specialised areas speaks to the fact that practitioners completed their basic training (with an average of 11 years in practice), but now require more training on techniques that are novel, sophisticated or innovative.

Perceptions regarding the cost of CPD activities may be relative to income and overall economic status of the participants. Nevertheless, it is important to note that cost issues are significant variables that have been linked as barriers to continuing education initiatives and compliance, ${ }^{[4,11]}$ especially as $>70 \%$ of participants in the current study were self-funding their CPD.

Table 8. Gender effects on selected variables

\begin{tabular}{|c|c|c|c|c|}
\hline Variables & $\chi^{2}$ & df & $p$-value & Cramer's V \\
\hline Problems accessing CPD & 3.33 & 1 & 0.068 & 0.128 \\
\hline Agreement with mandatory CPD & 4.26 & 1 & 0.039 & 0.146 \\
\hline Would undertake CPD regardless of legislation & 0.00 & 1 & 0.991 & 0.001 \\
\hline Continuing education needs currently met & 0.51 & 1 & 0.475 & 0.051 \\
\hline Have been audited by HPCSA & 11.65 & 1 & 0.001 & 0.241 \\
\hline Views of cost of CPD activities & 0.097 & 1 & 0.756 & 0.022 \\
\hline
\end{tabular}


The finding that significantly more participants in full-time private practice viewed CPD costs as excessive than those who were not in full-time private practice, could be viewed in the context of overall costs to such individuals, rather than simply cost of the CPD activity, as these practitioners lose income through closure of their practice if the activity takes place during the workday.

The report by almost half the participants that their CPD compliance had been audited by the HPCSA is indicative of the regulatory body's seriousness about continuing education. It is, however, concerning that about half of those selected for random audits had not met the CPD points requirement. The HPCSA does note, however, that practitioners who are found non-compliant are given a further 6 months to remedy their situation. ${ }^{[2]}$ That $\sim 13 \%$ of participants were themselves CPD providers is encouraging, and the relative ease that most report in the accrediting of their activities is an indication that the system functions better than it did several years previously, when the regulator had temporarily abandoned CPD owing to difficulties in managing the system.

\section{Conclusion}

The findings of this study of psychologists' experiences with the CPD system suggest an overall positive sentiment, barring cost and funding issues. The general consensus towards undertaking CPD activities, even if it was not mandatory, coupled with the self-identified improvements in theoretical, practical and ethics-related knowledge and skills, augurs well for the profession. The preference for peer-group learning formats is also encouraging. It is, therefore, recommended that CPD programmes include more specialised techniques, using more group-training formats, and pay more serious attention to cost reduction in such offerings. The latter can be better facilitated when arranged by universities and professional associations, which also address participant preferences noted in this study.

\section{Declaration. None.}

Acknowledgements. None.

Author contributions. The authors contributed jointly to conceptualising, executing and reporting on the research.

Funding. None.

Conflicts of interest. None.

1. Davids JM. Continuing professional development in nursing. MPhil thesis. Cape Town: Stellenbosch University 2006 2. Health Professions Council of South Africa. CPD overview. 2017. http://www.hpcsa.co.za/CPD (accessed 14 December 2017)

3. Balmer JT, Bellande BJ, Addleton RL, et al. The relevance of the alliance for CME competencies for planning organizing, and sustaining an interorganizational educational collaborative. J Contin Educ Health Pro 2011;31(Supp 1):S67-S75. https://doi.org/10.1002/chp.20150

4. Grehan J, Butler M-L, Last J, et al. The introduction of mandatory CPD for newly state registered diagnostic radiographers: An Irish perspective. Radiography 2018;24(2):115-121. https://doi.org/10.1016/j.radi.2017.09.007 5. Mulvey R. How to be a good professional: Existentialist continuing professional development (CPD). Br J Guid Counc 2013;41(3):267-276. https://doi.org/10.1080/03069885.2013.773961

6. Brown CA, Belfield CR, Field SJ. Cost effectiveness of continuing professional development in health care: A critical review of the evidence. BMJ 2002;324(7338):652-655. https://doi.org/10.1136/bmj. 324.7338 .652

7letcher M. Continuing education for healthcare professionals: Time to prove its worth. Prim Care Respir 2007;16(3):188-190. https://doi.org/10.3132/pcri.2007.00041

8. Balmer JT. The transformation of continuing medical education (CME) in the United States. Adv Med Educ Pract 2013;4:171-182. https://doi.org/10.2147/AMEP.S35087

9. Boud D, Hager P. Re-thinking continuing professional development through changing metaphors and location in professional practices. Stud Cont Educ Sciences 2012;34(1):17-30. https://doi.org/10.1080/0158037X.2011.608656 10. Abdul Samad N, Md Zain A, Osman R, et al. Malaysian private general practitioners' views and experiences on continuous professional development. Malays Fam Physician 2014;9(2):34-40.

11. Feldacker C, Pintye J, Jacob S, et al. Continuing professional development for medical, nursing, and midwifery cadres in Malawi, Tanzania and South Africa. PLOS ONE 2017;12(10):e0186074. https://doi.org/10.1371/journal. pone. 0186074

12. Pillay AL, Tooke L, Zank A. Continuing education needs and related variables among mental health professionals in South Africa. J Psychol Africa 2013;23(4):643-646. https://doi.org/10.1080/14330237.2013.10820681

13. Statistics South Africa. Mid-year population estimates 2017. Pretoria: StatsSA, 2017.

14. Brosig CL, Hilliard ME, Williams A, et al. Society of Pediatric Psychology workforce survey. J Pediatr Psychol 2017;42(4):355-363. https:///doi.org/10.1093/jpepsy/jsx051

15. Pillay AL, Kritzinger AM. The dissertation as a component in the training of clinical psychologists. S Afr J Psychol 2007;37(3):638-655.

16. Skinner K, Louw J. The feminization of psychology: Data from South Africa. Int J Psychol 2009;44(2):81-92. https:// doi.org/10.1080/00207590701436736

17. Hoffman DH, Carter DI, Viglucci Lopez CR, et al. Report to the Special Committee of the Board of Directors of the American Psychological Association: Independent Review Relating to APA Ethics Guidelines, National Security Interrogations, and Torture. Chicago, IL: Sidley Austin LLP, 2015.

18. Pillay AL. Psychology, ethics, human rights, and national security. S Afr J Psychol 2015;45(4):424-429. https://doi org/10.1177/0081246315611045

Accepted 26 April 2018 